\title{
Penyuluhan Warehouse Management pada UMKM melalui Perbaikan secara Berkelanjutan
}

\author{
Warehouse Management Counseling for MSMEs through Continuous Improvement
}

Monanda Wandita Rini*
Nessa Ananda
Department of Electronics Industry
Logistics Management, Politeknik
Negeri APP Jakarta, South Jakarta,
Jakarta Capital Special Region,
Indonesia
email: mona.wandita@gmail.com
Kata Kunci
Muda, Mura, Muri (3MU)
Pengelolaan gudang
Perbaikan berkelanjutan
Pergudangan
Keywords:
Muda, Mura, Muri (3MU)
Warehouse management
Continuous improvement
Warehouse

\begin{abstract}
Abstrak
Perkembangan dunia usaha yang semakin pesat menuntut adanya perbaikan yang harus dilakukan secara terus-menerus (continuous improvement). Penerapan continuous improvement tidak hanya dilakukan pada perusahaan besar, namun juga perlu dilakukan oleh UMKM (Usaha Mikro Kecil Menengah). Salah satu aktivitas yang perlu dikelola dengan baik oleh UMKM adalah aktivitas pergudangan. Pengelolaan gudang yang optimal dapat meningkatkan kinerja usaha dari UMKM. Namun demikian pengetahuan dan kesadaran akan konsep continuous improvement belum dimiliki dengan optimal oleh UMKM. Hal ini mengakibatkan pengelolaan gudang belum dilakukan dengan optimal oleh UMKM. Kegiatan pengabdian masyarakat ini bertujuan untuk memberikan pengetahuan kepada UMKM tentang cara mengidentifikasi Muda, Mura, Muri dan cara untuk melakukan continuous improvement dalam pengelolaan gudang. Metode pelaksanaan kegiatan dilakukan dengan observasi dan penyuluhan secara langsung kepada UMKM. Kegiatan pengabdian masyarakat ini dilakukan selama dua hari. Kegiatan penyuluhan dilakukan pada tanggal 27 April dengan diikuti oleh pemilik dan pegawai UMKM Boneka di Bogor. Penyuluhan dilakukan dengan memberikan materi tentang konsep continuous improvement dan identifikasi Muda, Mura, Muri serta dilanjutkan dengan sesi diskusi.
\end{abstract}

\begin{abstract}
The business development that is getting faster needs continuous improvements. Implementation of continuous improvement is carried out in large companies and needs to be carried out by MSMEs (Medium Small Micro Enterprises). One activity that needs to be appropriately managed by MSMEs is warehousing. Optimal warehouse management can improve MSME business performance. However, MSMEs do not own knowledge and awareness of continuous improvement optimally. This resulted in warehouse management has not performed optimally by MSMEs. This community service activity aims to provide knowledge to MSMEs about how to identify Muda, Mura, Muri and how to make continuous improvements in warehouse management. Implementing activities is carried out by direct observation and counseling to MSMEs. This community service activity was carried out for two days. The counseling activity was carried out on April 27, attended by owners and employees of Puppet MSMEs in Bogor. The counseling was carried out by providing material on the concept of continuous improvement and identification of Muda, Mura, Muri and continued with a discussion session.
\end{abstract} (http://creativecommons.org/licenses/by-sa/4.0/). DOI: https://doi.org/10.33084/pengabdianmu.v7i1.2302

\section{PENDAHULUAN}

Dunia usaha yang semakin berkembang menuntut adanya perubahan yang dinamis dalam suatu usaha. Usaha yang akan bertahan harus bisa melakukan perubahan dengan melakukan perbaikan secara terus menerus (continuous improvement). Continuous improvement merupakan konsep tentang perbaikan atau peningkatan diri secara terus-menerus yang mendapatkan perhatian, karena telah menjadi bagian dari karakteristik persaingan global agar berhasil memajukan produksi barang, layanan jasa dan kualitas proses dalam suatu bisnis (Rusdi, 2018). Perbaikan yang dilakukan secara terus- 
menerus dapat dimulai dari tindakan kecil. Budaya kerja continuous improvement juga dikenal dengan istilah Kaizen. Budaya Kerja Kaizen telah banyak memberikan perubahan pada banyak perusahaan, khususnya perusahaan Jepang. Perusahaan yang mempelopori Budaya Kerja Kaizen ini adalah Toyota (Tri et al., 2019). Dengan menerapkan Kaizen, Toyota dapat terus mempertahankan bisnis yang dilakukan dan terus berkembang.

Penerapan continuous improvement tidak hanya dapat dilakukan oleh perusahaan-perusahaan besar saja, usaha mikro kecil menengah (UMKM) juga perlu memiliki pemahaman akan konsep continuous improvement hingga menerapkan continuous improvement dalam proses bisnis yang dilakukan. Namun demikian, pengetahuan tentang konsep continuous improvement belum dimiliki dengan optimal oleh UMKM. Begitu juga dengan kesadaran untuk menerapkan continuous improvement yang belum dilakukan dengan optimal oleh UMKM. Kegiatan pengabdian masyarakat ini, dapat menjadi salah satu cara untuk berbagi informasi dan pengetahuan kepada UMKM agar dapat meningkatkan awareness yang terkait dengan continuous improvement (Ishak, 2015).

Dalam menjalankan usaha, banyak UMKM yang telah memiliki gudang untuk menyimpan barang-barang yang dibutuhkan untuk produksi ataupun barang jadi yang siap untuk dikirim. Menurut Warman (2012), gudang adalah bangunan yang digunakan untuk menyimpan barang dagangan. Pergudangan adalah kegiatan menyimpan di dalam gudang. Sedangkan menurut Hudori (2017), gudang adalah suatu fungsi penyimpanan berbagai macam jenis produk yang memiliki unit-unit penyimpanan dalam jumlah besar maupun yang kecil dalam jangka waktu saat produk dihasilkan oleh pabrik (penjual) dan saat produk dibutuhkan oleh pelanggan atau stasiun kerja dalam fasilitas pembuatan. Fungsi utama dari gudang adalah sebagai tempat untuk menyimpan bahan mentah (raw material), barang setengah jadi (work in process), dan barang jadi (finished goods).

Menurut Siahaya (2013), manajemen pergudangan adalah bagian dari manajemen logistik dan manajemen rantai pasok. Manajemen pergudangan ini merupakan pengelolaan terhadap kegiatan penerimaan, penyimpanan, perawatan, pengiriman, dan penataan barang pada tempat tertentu. Sedangkan menurut Pandiangan (2017), manajemen pergudangan merupakan suatu sistem pengelolaan gudang yang mengatur proses penanganan barang mulai dari penerimaan sampai dengan pengiriman barang. Tujuan manajemen pergudangan yaitu untuk mengoptimalkan pemanfaatan ruang pada gudang, memastikan efektivitas pegawai dalam bekerja dan dalam menggunakan peralatan gudang, serta menjamin efektivitas pergerakan barang di gudang. Selain itu, manajemen pergudangan juga bertujuan untuk menangani dan mengendalikan material dalam gudang (Pitoy et al., 2020).

Keberadaan gudang pada dunia usaha termasuk UMKM diperlukan untuk mengantisipasi fluktuasi permintaan, kenaikan harga bahan baku, mengurangi ongkos transportasi dan juga untuk menjamin pemenuhan kebutuhan konsumen. Namun dalam operasionalnya, keberadaan gudang memiliki beberapa tantangan di antaranya resiko kerusakan barang, lamanya waktu proses pada aktivitas pergudangan yang disebabkan sistem penyimpanan yang belum tertata baik, utilitas gudang yang rendah, serta resiko kecelakaan kerja pada gudang. Tantangan tersebut menjadi hal yang perlu dipertimbangkan dalam mengelola gudang.

Dalam melakukan continuous improvement di gudang, proses pengidentifikasian Muda, Mura, Muri(3MU) perlu dilakukan. Sebelum mengidentifikasi 3MU pada UMKM, pemahaman konsep 3MU perlu dilakukan terlebih dahulu pada UMKM. Menurut Ngadono (2018), Muda adalah segala kegiatan yang bernilai mubasir atau aktivitas pemborosan yang tidak menambahkan nilai pada produk atau jasa. Sementara Mura dapat diartikan sebagai suatu proses yang tidak merata atau tidak teratur dalam kegiatan proses produksi dan Muri dapat diartikan sebagai pembebanan yang berlebihan atau melampaui batas kemampuan para pekerja dalam melakukan pekerjaannya. Pemahaman konsep 3MU yang belum optimal dapat membuat proses identifikasi aktivitas pemborosan belum dilakukan di gudang UMKM.

Penerapan continuous improvement di pergudangan perlu dilakukan. Salah satu metode continuous improvement yang dapat digunakan adalah PDCA. Penelitian yang dilakukan oleh Widodo dan Fardiansyah (2019) menggunakan metode PDCA untuk menyelesaikan permasalahan pada proses handover di warehouse. Selain itu, penerapan continuous improvement juga dapat dilakukan untuk meningkatkan jumlah produksi pada perusahaan kaca pengaman (Ngadono, 2018). Implementasi budaya kerja Kaizen pada perusahaan manufaktur di Jepang juga dapat meningkatkan kinerja perusahaan (Tri et al., 2019). 
Penerapan continuous improvement juga dapat dilakukan pada dunia Pendidikan untuk meningkatkan mutu pendidikan di pedesaan (Rusdi, 2018). Oleh karena itu penerapan continuous improvement dapat dilakukan pada semua sektor usaha dan bidang.

Kegiatan pengabdian masyarakat ini diharapkan dapat memberikan pemahaman kepada UMKM, khususnya UMKM Boneka di Bogor supaya dapat mengelola gudang yang dimiliki dengan optimal, dapat mengidentifikasi 3MU, dan menerapkan continuous improvement. Selain itu, kegiatan pengabdian masyarakat ini diharapkan dapat meningkatkan awareness UMKM terhadap pengelolaan gudang dengan continuous improvement. Dengan penerapan continuous improvement, diharapkan UMKM Boneka di Bogor dapat mengurangi hingga mengeliminasi pemborosan di pergudangan, meningkatkan mutu produk dan meningkatkan hubungan yang baik antara pemilik dan pegawai.

\section{METODE}

Kegiatan pengabdian kepada masyarakat pada UMKM Boneka dilaksanakan dengan beberapa tahap diantaranya yaitu pembuatan proposal, visitasi dan koordinasi dengan UMKM, persiapan materi penyuluhan, dan pelaksanaan kegiatan penyuluhan. Jumlah peserta penyuluhan yaitu 20 orang yang terdiri dari pemilik dan pegawai UMKM Boneka di Kota Bogor. Kegiatan penyuluhan dibagi menjadi beberapa sesi dengan total waktu 3,5 jam. Adapun tahapan dari kegiatan pengabdian masyarakat yang dilakukan dapat ditunjukkan pada Tabel I.

Tabel I. Tahapan kegiatan pengabdian masyarakat

\begin{tabular}{lll}
\hline No & \multicolumn{1}{c}{ Kegiatan } & \multicolumn{1}{c}{ Peran anggota } \\
\hline 1. & $\begin{array}{l}\text { Melakukan } \begin{array}{l}\text { kunjungan dan } \\
\text { koordinasi dengan UMKM } \\
\text { Mempersiapkan materi penyuluhan }\end{array} \\
\text { 2. }\end{array}$ & $\begin{array}{l}\text { Pada tahapan ini dilakukan kunjungan ke UMKM untuk mengetahui gambaran kondisi } \\
\text { UMKM serta memastikan kesediaan UMKM dalam kegiatan pengabdian masyarakat. } \\
\text { Pada tahapan ini dipersiapkan materi terkait continuous improvement dan Muda, Mura, } \\
\text { 3. }\end{array} \quad \begin{array}{l}\text { Muri yang dapat digunakan untuk mengoptimalkan pengelolaan gudang di UMKM. } \\
\text { Pada kegiatan ini dilakukan penyuluhan tentang continuous improvement dan Muda, } \\
\text { Mura, Muri setelah melakukan pengamatan pada gudang UMKM. }\end{array}$ \\
\hline
\end{tabular}

\section{HASIL DAN PEMBAHASAN}

Kegiatan penyuluhan dilakukan pada tanggal 26 April yang berlokasi di UMKM yang memproduksi boneka di Bogor dengan jumlah pegawai sebanyak 20 orang. Kegiatan penyuluhan ini dibagi menjadi 4 sesi, yaitu pembukaan, observasi, penyampaian materi penyuluhan, dan diskusi. Sesi pembukaan dimulai pada pukul 09.00 sampai pukul 09.30 WIB. Kegiatan pengabdian kepada masyarakat ini dibuka oleh Ketua Program Studi Manajemen Logistik Industri Elektronika. Berdasarkan hasil pengamatan, UMKM Boneka memiliki empat jenis gudang yaitu gudang bahan, gudang kardus, gudang kapas, dan gudang barang sisa.

1. Gudang Bahan

Gudang bahan digunakan untuk menyimpan berbagai jenis kain yang menjadi bahan utama pembuatan boneka. Pada gudang bahan, peletakan kain masih belum rapi dan belum sesuai dengan tempatnya, hal tersebut dikarenakan peletakan yang terburu-buru dan setiap kotak belum disertai dengan label jenis kain. Selain itu pencahayaan dan ventilasi masih kurang optimal sehingga ketika masuk ke dalam gudang akan terlihat gelap dan terasa pengap. Oleh karena itu perlu adanya identifikasi 3MU pada gudang bahan agar dapat dilakukan continuous improvement terhadap kendala-kendala yang ada pada gudang UMKM Boneka.

2. Gudang Kardus

Gudang kardus digunakan untuk menyimpan kardus yang berfungsi sebagai pelindung produk selama penyimpanan di gudang hingga produk dikirimkan ke konsumen. Selain sebagai tempat menyimpan kardus, gudang ini juga digunakan untuk menyimpan boneka yang telah siap kirim untuk kemudian dikemas. Pada gudang kardus, penempatan kardus belum dilakukan dengan optimal sehingga menyebabkan gudang menjadi kurang rapi sehingga 
dapat menghambat pergerakan keluar masuk gudang, selain itu untuk kebersihan gudang masih perlu ditingkatkan. Pada gudang kardus, terdapat inventory yang berlebih terlihat dari banyak kardus yang menumpuk. Jika kardus terlalu lama tidak digunakan maka dapat rusak sehingga berdampak pada biaya yang harus dikeluarkan untuk memesan kembali kardus.

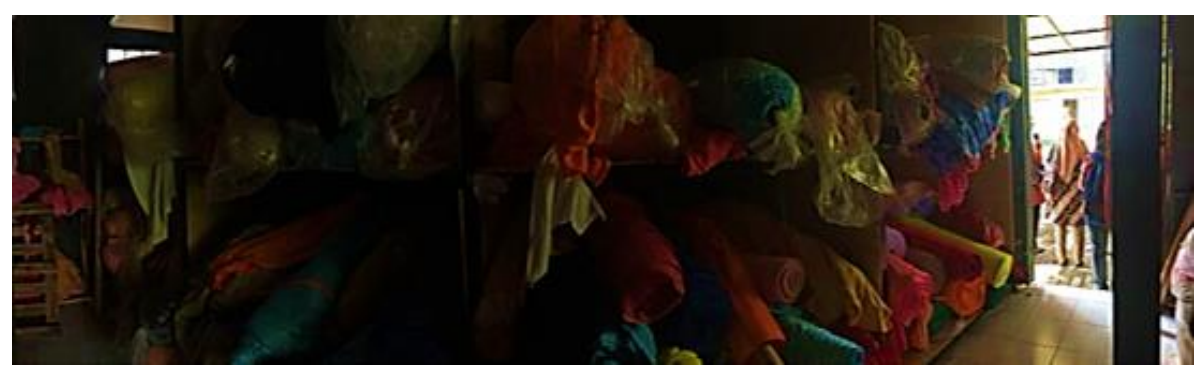

Gambar 1. Gudang bahan di UMKM boneka

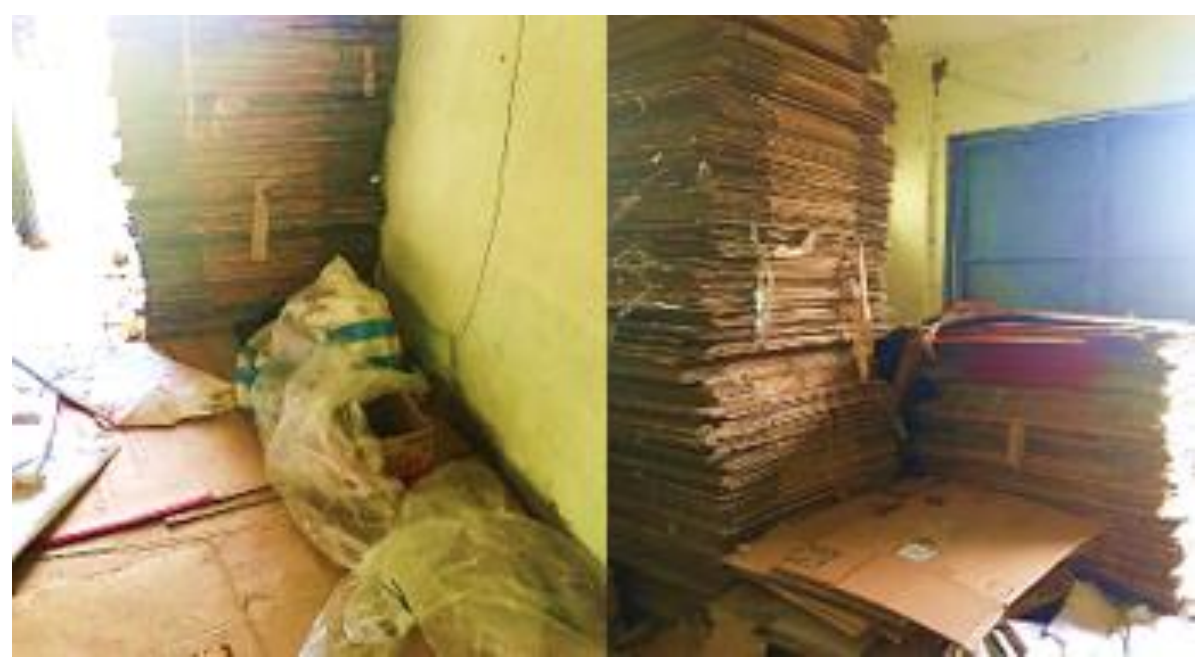

Gambar 2. Gudang kardus di UMKM boneka

3. Gudang Kapas

Gudang kapas digunakan untuk menyimpan karung yang berisi kapas. Kapas nantinya digunakan sebagai bahan untuk mengisi boneka yang telah dijahit polanya. Pada gudang kapas, karung bekas kapas yang sudah digunakan ditaruh bersama dengan karung kapas yang masih berisi kapas, selain itu karung yang berisi kain-kain sisa menjahit (kain perca) ditaruh bersamaan dengan karung yang berisi kapas. Hal tersebut dapat mengakibatkan terjadinya kekeliruan pada saat pengambilan karung yang berisi kapas sehingga akan mengakibatkan lead time produksi bertambah. Penempatan barang di gudang kapas belum optimal dari segi keamanan karena di lantai gudang banyak terdapat sisa-sisa karung yang dapat menyebabkan pegawai terpeleset ketika mengambil karung kapas.

4. Gudang Barang Sisa

Gudang barang sisa digunakan untuk menyimpan produk boneka yang tidak terjual ataupun apabila terdapat kelebihan produksi. Pada gudang barang sisa, penempatan boneka perlu untuk dilakukan penataan agar dapat tersusun dengan baik. 


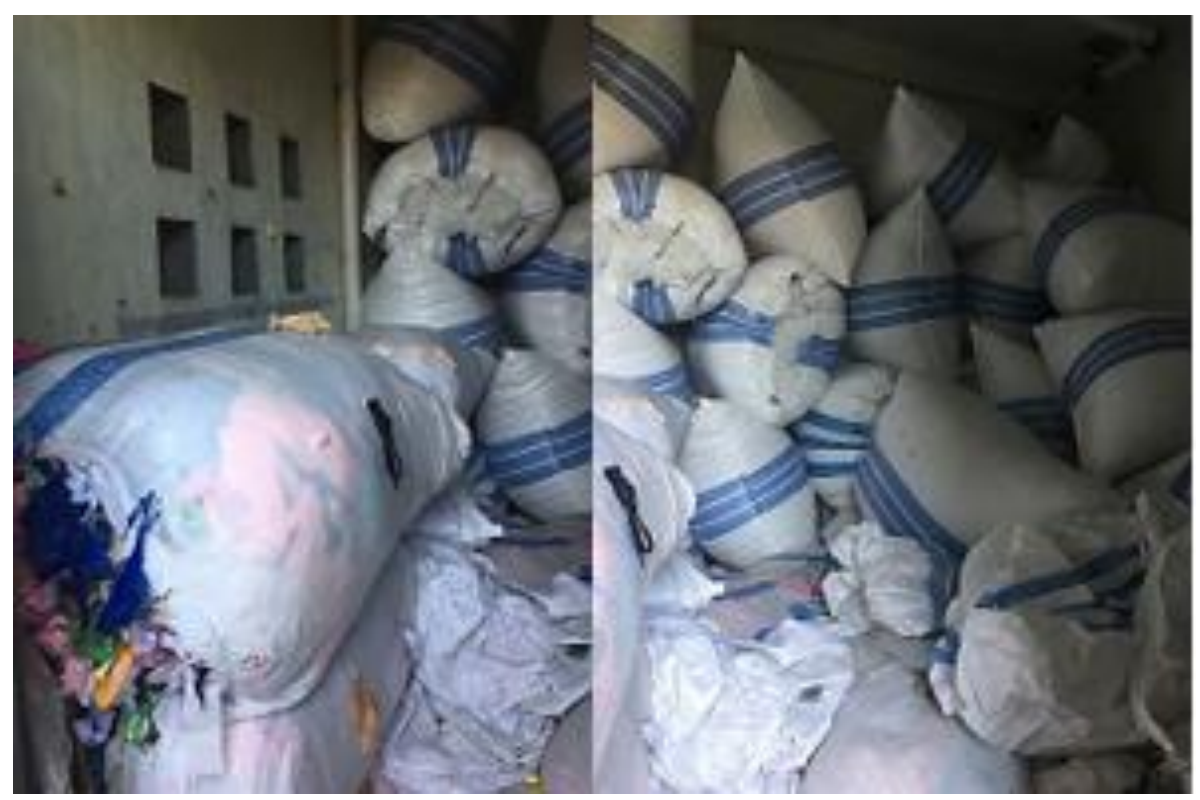

Gambar 3. Gudang kapas di UMKM boneka

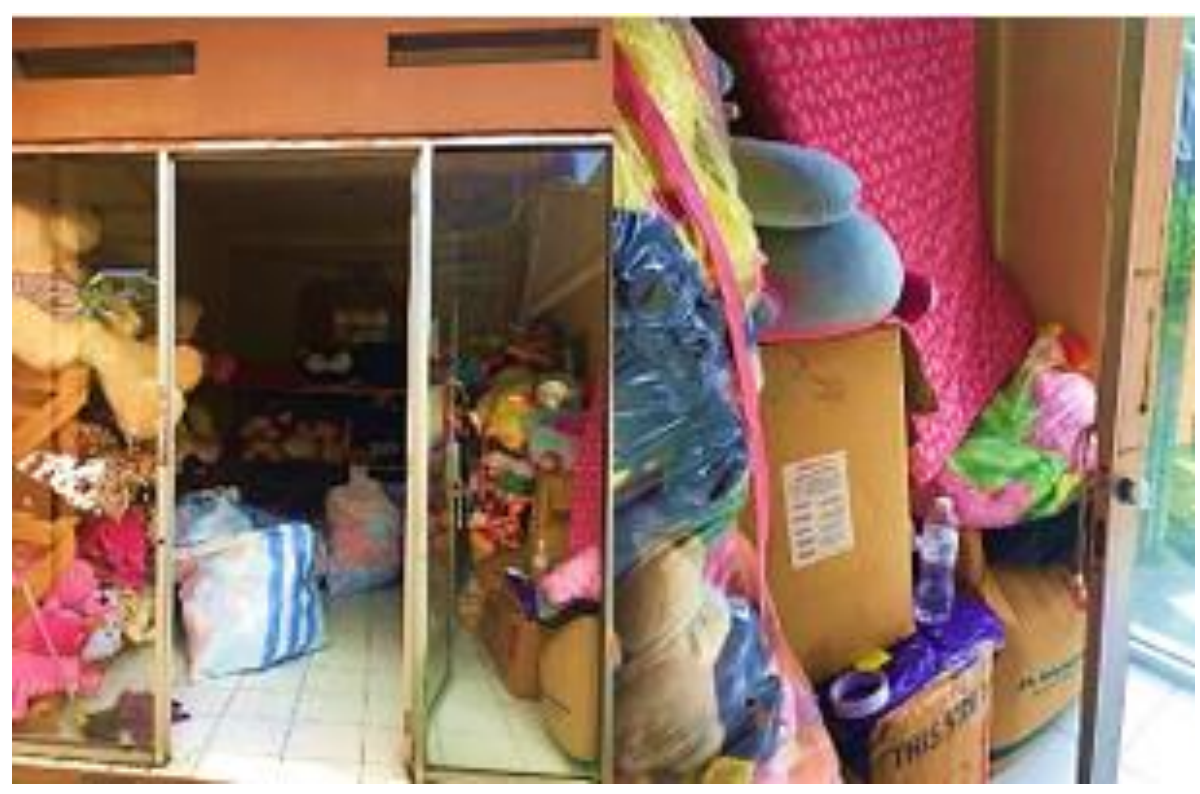

Gambar 4. Gudang barang sisa di UMKM boneka

Setelah observasi dilakukan, selanjutnya dimulai sesi ketiga dan keempat selama dua jam yaitu dengan pelaksanaan penyuluhan serta diskusi yang dilakukan secara langsung kepada pemilik dan pegawai UMKM Boneka. Pada saat penyuluhan dilakukan penjelasan maksud dan tujuan perlunya suatu perusahaan memperhatikan konsep continuous improvement (Kaizen) dan 3MU pada gudang UMKM Boneka. Pada presentasi pertama disampaikan materi mengenai pengertian continuous improvement (Kaizen), manfaat continuous improvement, konsep penerapan continuous improvement, metode-metode continuous improvement, PDCA (Plan-Do-Check-Action), manfaat serta tahapan-tahapan penerapan PDCA. Pada presentasi kedua disampaikan materi mengenai pengertian 3MU, cara mengidentifikasi 3MU, dan Fishbone Diagram. Kemudian pada sesi keempat dilanjutkan dengan diskusi mengenai cara menerapkan konsep continuous improvement (Kaizen) dan cara untuk mengindentifikasi 3MU di gudang. 


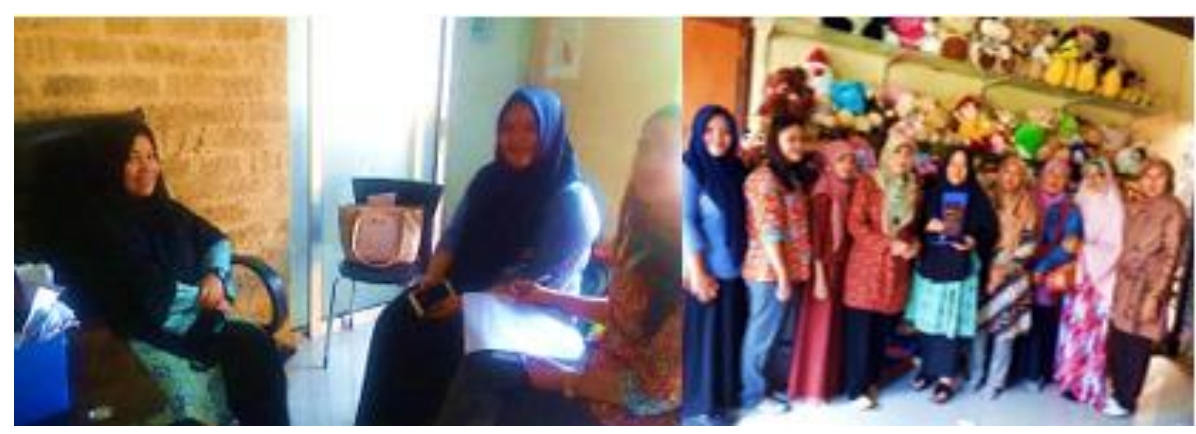

Gambar 5. Kegiatan pengabdian kepada masyarakat di UMKM boneka

\section{KESIMPULAN}

Dalam melaksanakan pengabdian masyarakat pada UMKM Boneka di Kota Bogor diharapkan penyuluhan yang telah dilakukan dapat memberikan tambahan pengetahuan dan meningkatkan awareness mengenai pentingnya pengelolaan gudang yang baik, terutama dalam mengidentifikasi 3MU untuk peningkatan berkelanjutan (continuous improvement). Kegiatan penyuluhan ini diharapkan dapat memberikan peningkatan kemampuan dalam pengelolaan gudang di UMKM Boneka dalam segi kerapian, keteraturan penempatan barang, meningkatkan keamanan dalam proses pergudangan dan mengurangi pemborosan (waste).

\section{UCAPAN TERIMA KASIH}

Terimakasih kami sampaikan kepada Politeknik APP Jakarta yang telah memberikan dukungan sehingga kegiatan pengabdian kepada masyarakat ini dapat terlaksana dengan baik dan atas partisipasi dalam kegiatan abdimas. Terima kasih juga kami sampaikan kepada UMKM Boneka di Kota Bogor atas partisipasi dan kesediaannya dalam kegiatan pengabdian kepada masyarakat ini.

\section{REFERENSI}

Hudori, M. 2017. Penerapan Kaizen untuk Mempermudah Pengambilan Barang pada Gudang Finished Goods. Industrial Engineering Journal. 6(2):4-9. https:// doi.org/10.53912/iejm.v6i2.159

Ishak, A.A. 2015. Totalitas Implementasi Rumusan Continuous Improvement Untuk Peningkatan Daya Saing Produk UMKM. In Proceeding Seminar Nasional \& Call for Papers Sustainable Competitive Advantage 5 (SCA 5). Purwokerto: Universitas Jenderal Soedirman; 1-17.

Ngadono, T.S. 2018. Penerapan Kaizen pada Line Trimming untuk Meningkatkan Jumlah Produksi Kaca Pengaman. Operations Excellence : Journal of Applied Industrial Engineering. 10(2):197-208

Pandiangan, S. 2017. Operasional Manajemen Pergudangan. Jakarta: Mitra Wacana Media

Pitoy, H.W.W., Jan, A.B.H., Sumarauw, J.S.B. 2020. Analisis Manajemen Pergudangan Pada Gudang Paris Superstore Kotamobagu. Jurnal EMBA : Jurnal Riset Ekonomi, Manajemen, Bisnis dan Akuntansi. 8(3):252-260. https://doi.org/10.35794/emba.v8i3.29929

Rusdi. 2018. Continues Improvement Sebagai Upaya Dalam Meningkatkan Mutu Pendidikan Pedesaan. Al-Tanzim : Jurnal Manajemen Pendidikan Islam. 2(2):150-160. https://doi.org/10.33650/al-tanzim.v2i2.396

Siahaya, W. 2013. Supply Chain Manajemen. Jakarta: In Media 
Tri, D., Rakhmanita, A., Anggraini, A. 2019. Implementasi Kaizen Dalam Meningkatkan Kinerja (Studi Kasus Perusahaan Manufaktur di Tangerang). Jurnal Ecodemica : Jurnal Ekonomi, Manajemen, dan Bisnis. 3(2):198-206. https://doi.org/10.31294/jeco.v3i2.6077

Warman, J. 2012. Manajemen Pergudangan. Jakarta: Lembaga Pendidikan dan Pembinaan Manajemen - Pustaka Sinar Harapan

Widodo, T., Fardiansyah, I. 2019. Implementasi Continuous Improvement Dengan Menggunakan Metode PDCA pada Proses Handover di Warehouse PT. ABC. Journal Industrial Manufacturing. 4(1):37-44. http://dx.doi.org/10.31000/jim.v4i1.1243 